Review

\title{
Assessing the incidence of gastroenteritis among elderly people living in long term care facilities
}

\author{
M.D. Kirk ${ }^{\mathrm{a}, \mathrm{b}, *}$, G.V. Hall ${ }^{\mathrm{a}, \mathrm{c}}$, M.G.K. Veitch ${ }^{\mathrm{d}}$, N. Becker ${ }^{\mathrm{a}}$ \\ ${ }^{a}$ National Centre for Epidemiology and Population Health, Australian National University, Canberra, Australia \\ ${ }^{\mathrm{b}}$ OzFoodNet, Australian Government Department of Health and Ageing, Canberra, Australia \\ ${ }^{c}$ Medical School, Australian National University, Canberra, Australia \\ ${ }^{\mathrm{d}}$ Microbiological Diagnostic Unit Public Health Laboratory, University of Melbourne, Melbourne, Australia
}

\section{A R T I C L E I N F O}

\section{Article history:}

Received 20 October 2009

Accepted 2 April 2010

Available online $\mathrm{xxx}$

\section{Keywords:}

Diarrhoea

Elderly

Gastroenteritis

Meta-analysis

Nursing home

\begin{abstract}
S U M M A R Y
We conducted a systematic review and meta-analysis of the literature in order to estimate the incidence of gastroenteritis in long term care facility (LTCF) residents from published accounts of infection surveillance. PubMed, Web of Science and Google Scholar were searched using keywords 'long-term care facility', 'nursing home', 'gastroenteritis', 'surveillance', and 'incidence'. We manually searched reference lists of all articles included. The number of cases of gastroenteritis and bed-days under surveillance was recorded so as to calculate incidence and assess the influence of the study country and case definition using random effects metaanalysis and regression. We included one trial and 14 surveillance studies in the analysis, with $47 \%$ (7/15) conducted after 1995 . One study focused only on gastroenteritis in residents; the remainder considered a range of infections. There were 2071330 combined bed-days under surveillance and 717 cases of gastroenteritis. In all, 194 cases were associated with 10 outbreaks during these studies. We observed heterogeneity between studies, which may have been due to unreported clustering of gastroenteritis cases. The mean incidence of gastroenteritis in LTCF residents was 0.40 (95\% confidence interval: $0.27-0.56$ ) episodes per 1000 beddays. Investigators conducting studies in the USA reported incidence three times lower than investigators in other countries. Use of a case definition developed specifically for LTCFs was not associated with a higher incidence of gastroenteritis. From our analysis, residents could expect to experience gastroenteritis once every $5-10$ years, which is a lower rate than that estimated from point prevalence surveys. New studies are needed to better assess the incidence and causes of gastroenteritis in LTCF residents.
\end{abstract}

Crown Copyright $\odot 2010$ Published by Elsevier Ltd on behalf of The Hospital Infection Society. All rights reserved.

\section{Introduction}

Residents of long term care facilities (LTCFs) may be vulnerable to infections, including those affecting skin and respiratory, urinary and gastrointestinal tracts. ${ }^{1}$ Gastroenteritis is usually mild and selflimiting, but may be more likely to result in hospitalisation and death among elderly people, particularly those in LTCFs, due to

\footnotetext{
* Corresponding author. Address: Australian National University, Canberra, Australian Capital Territory 0200, Australia. Tel.: +61 26289 2746; fax: +61 26289 2500.

E-mail address: martyn.kirk@anu.edu.au (M.D. Kirk).
}

frailty and chronic illnesses. ${ }^{2-4}$ LTCF residents acquire gastroenteritis from a range of sources, including other infected persons or animals, or contaminated environments, foods or water. ${ }^{5}$

Many prospective surveillance studies in LTCF residents have attempted to estimate the burden and relative importance of different infectious conditions. ${ }^{6,7}$ Facility practitioners conduct surveillance for infectious diseases to monitor facility performance and detect outbreaks. ${ }^{8}$ Surveillance studies published in the literature commonly use definitions for infectious conditions developed at a Canadian consensus conference in 1991 developed specifically for the long term care setting, known as 'McGeer's definitions'. Studies conducted prior to this time used definitions that may have been less sensitive. ${ }^{9-11}$ To meet McGeer's definition

0195-6701/\$ - see front matter Crown Copyright @ 2010 Published by Elsevier Ltd on behalf of The Hospital Infection Society. All rights reserved. doi:10.1016/j.jhin.2010.04.009 
for gastroenteritis, a resident must have two or more episodes of diarrhoea or vomiting in 24 hours, or have a stool specimen positive for a pathogen or toxin with at least one symptom consistent with the agent. Participants at the Canadian consensus conference expressed reservations about this definition of gastroenteritis, as it was 'generally thought that because gastrointestinal symptoms are common, and viral gastroenteritis is often a mild disease, any definition that captured most viral gastroenteritis would also label many non-infectious episodes as infections'. ${ }^{10}$ Despite widespread use of this definition since the conference, validation studies have not been published.

Gastroenteritis outbreaks affecting LTCF residents may have serious consequences and cause concern for governments and the public. ${ }^{4}$ In recent years the high frequency of outbreaks in LTCFs has been widely recognised, but less is known about the occurrence of sporadic gastroenteritis. ${ }^{5}$ In this paper, we systematically review the literature to summarise studies examining gastroenteritis in LTCF residents and conduct a meta-analysis to estimate the pooled mean incidence of this condition.

\section{Methods}

We searched PubMed, Web of Science and Google Scholar for article titles published in any language. All searches were started with the terms 'long-term care' or 'nursing home' and then followed by combinations of 'diarrhoea', 'gastroenteritis', 'infection', 'surveillance', and 'incidence'. Relevant abstracts were reviewed for retrieval of a full article. We manually searched reference lists of all articles to identify further relevant studies on incidence. All articles considered for inclusion were assessed by two reviewers (M.D.K. and G.V.H.) and studies were included only where there was agreement.

For the purpose of this review, an LTCF was defined as an institution providing health care to elderly people unable to manage independently in the community and included nursing homes and chronic care facilities. ${ }^{8}$ In the review, we included studies that represented prospective surveillance of gastroenteritis in LTCF residents, and the methods and case definitions used for surveillance were clearly stated. We excluded retrospective studies and cross-sectional surveys of infection prevalence from the review. We excluded studies where investigators did not report gastroenteritis separately in either the methods or results; the case definition was poorly described; or they combined in the numerator the number of episodes of gastroenteritis with other conditions, such as diverticulitis, cholecystitis and intra-abdominal infection.

Relevant data from articles were extracted, including the country and year of study, the case definition used, the number of facilities under surveillance, the number of resident bed-days, the number of episodes of gastroenteritis, and any clustering of cases that was observed. Where study investigators did not report the person-time under study, we divided the number of cases of gastroenteritis by the reported incidence per 1000 bed-days to estimate the number of bed-days for further analysis.

We used a Freeman-Tukey arcsine transformation of the incidence of gastroenteritis reported in each individual study to stabilise the variances and bring the characteristics of the transformed data close to those of the normal distribution. ${ }^{12}$ The arcsinetransformed product $(t)$ was calculated by:

$t=\arcsin (r / n+1)^{1 / 2}+\arcsin ((r+1) /(n+1))^{1 / 2}$,

where $r$ represented the number of gastroenteritis events occurring during the study and $n$ the number of bed-days under surveillance. Transformed gastroenteritis incidence was entered as a random effect in meta-analysis and heterogeneity of study findings assessed using the $I^{2}$ statistic. ${ }^{13}$ Meta-regression was used to assess the importance of the country in which the study was conducted, the case definition used, whether investigators documented outbreaks, and the incidence of gastroenteritis if the study was conducted after 1995. Where predictors significantly affected transformed incidence rates, meta-analyses were stratified. We back-transformed results to calculate pooled estimates of the mean incidence of gastroenteritis in LTCF residents per 1000 bed-days. ${ }^{14}$ Data were analysed in Stata version 10.1 (Statacorp., College Station, TX, USA).

\section{Results}

As a result of the electronic search, we examined 559 article titles and 37 abstracts. Figure 1 summarises the selection process and shows the number of articles included in the review. $6,9,11,15-26$ In our final analysis, we included one intervention trial and 14 studies where gastroenteritis was an outcome of healthcare-associated infection surveillance (Table I).

Eight surveillance studies were conducted in the 1980s, two in the 1990s, four studies since 2000, and one published in 2007 did not record when it was conducted. The 15 studies were conducted in Brazil (one), Canada (two), Germany (two), Norway (one) and the USA (nine). All studies reported similar methods of surveillance and reporting cases of gastroenteritis. Most investigators used trained infection control practitioners to collect data. The median number of residents under surveillance was 403 (range: 55-1273), and 60\% $(9 / 15)$ of studies were conducted in one or two facilities. The median duration of study was 12 months (range: 6-36 months).

The median number of resident bed-days under surveillance for these 15 studies was 74370 bed-days (range: 15 218-472 019) and the median incidence of gastroenteritis was 0.38 episodes per 1000 bed-days (range: $0.04-1.9$ episodes per 1000 bed-days; Table I). In studies comparing all infections acquired while living in long term care, gastroenteritis represented a median of $7 \%$ of all infections (range: $1-21 \%$ ).

In total, there were 2071330 bed-days under surveillance in the 15 studies and investigators detected 717 cases of gastroenteritis. The pooled estimate of the mean gastroenteritis incidence from meta-analysis was 0.40 (95\% CI: $0.27-0.56$ ) events per 1000 beddays. We observed considerable variation of reported incidence between studies, which reflected a high degree of heterogeneity $\left(I^{2}=95.7 \%\right)$.

Investigators noted clustering of gastroenteritis cases in $40 \%$ $(6 / 15)$ of studies, with four investigators reporting one outbreak, and two reporting three outbreaks. No investigator reported how an outbreak was defined. All investigators reported the number of cases involved in the outbreak, except for one study where we estimated the number of cases from the published epidemic curve. ${ }^{20}$ We estimated that a total of 194 cases were associated with these 10 outbreaks.

Six studies used a case definition based on a Canadian consensus conference reported by McGeer et al., with the remainder using self-constructed definitions or modified from Centers for Disease Control and Prevention (Table I). ${ }^{10,27}$ In regression analysis, the case definition used did not $(P=0.7)$ significantly affect incidence rates. Similarly, whether investigators reported clustering of cases $(P=0.6)$ or the study was conducted after $1995(P=0.7)$ did not significantly affect incidence rates.

The mean rate of gastroenteritis for studies conducted in the USA was 0.23 (95\% CI: $0.15-0.35$ ) cases per 1000 bed-days, which was significantly lower than for studies conducted in other countries where the mean rate was 0.74 (95\% CI: 0.39-1.2) cases per 1000 bed-days (Figure 2). 


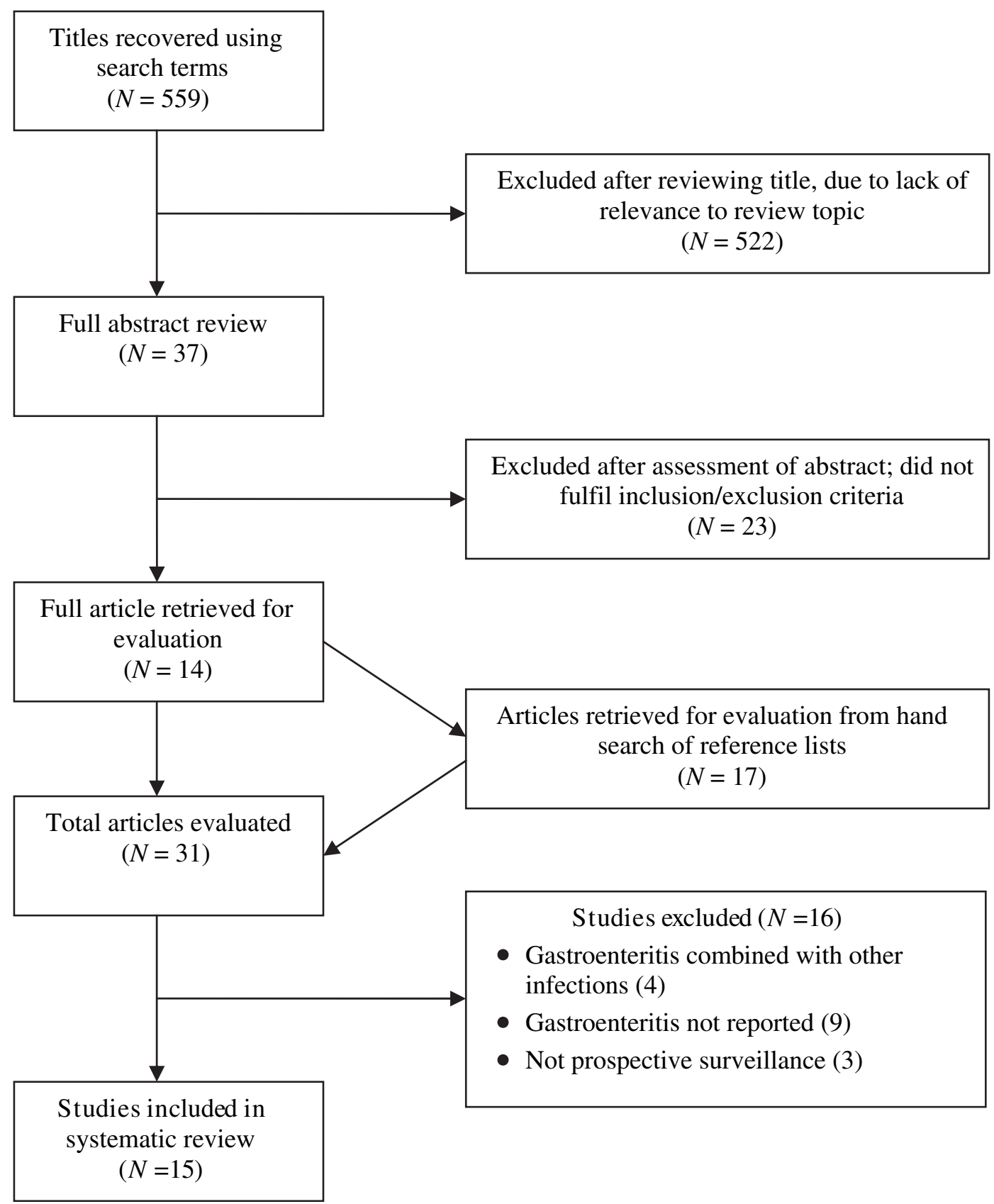

Figure 1. Flow diagram of studies identified and included in systematic review examining the incidence of gastroenteritis in residents of long term care facilities.

\section{Discussion}

We were surprised to find how rarely gastroenteritis was reported among LTCF residents in these studies, given that these facilities are one of the most common settings of reported outbreaks of gastroenteritis in many countries. ${ }^{28,29}$ We estimated that LTCF residents experience approximately one episode every $5-10$ years. This reported rate was lower than that found in studies of gastroenteritis in persons aged $>65$ years living in the community. $^{30}$

In our review, only two studies in Germany reported incidence rates ( 0.45 and 0.52 episodes per person per year) comparable to that found in community-based studies in developed countries. ${ }^{6,17,30}$ It is unclear why studies conducted outside the USA reported higher incidence. It is possible that the higher incidence is due to different pathogens causing disease in different countries, or greater recognition of gastroenteritis as a nosocomial syndrome in LTCF residents outside the USA. There is also the possibility of subtle differences in methods used by investigators that we were unable to observe from published accounts.

Our estimate of incidence was also lower than that observed in point prevalence surveys, which we excluded from our review. In our literature search, we identified five point prevalence surveys reporting cases of gastroenteritis, along with other infections. ${ }^{18,21,31-33}$ The point prevalence of gastroenteritis in residents reported by these studies varied from $0.5 \%$ to $3 \%$. If we assume that an episode of gastroenteritis lasts an average of three days in an elderly person, then estimates of incidence from these point prevalence studies would range from 1.4 to 8 episodes per 1000 bed-days. It is important to recognise that these point 
Table I

Incidence of gastroenteritis among long term care facility residents from prospective surveillance reported in the literature

\begin{tabular}{|c|c|c|c|c|c|c|c|c|c|c|}
\hline Study period and country & $\begin{array}{l}\text { Surveillance } \\
\text { methods }\end{array}$ & $\begin{array}{l}\text { Data collection } \\
\text { frequency }\end{array}$ & Case definition & $\begin{array}{l}\text { No. of } \\
\text { facilities }\end{array}$ & $\begin{array}{l}\text { Residents under } \\
\text { surveillance }\end{array}$ & $\begin{array}{l}\text { No. of bed- } \\
\text { days }\end{array}$ & $\begin{array}{l}\text { Cases of } \\
\text { gastroenteritis }\end{array}$ & $\begin{array}{c}\text { Outbreak } \\
\text { associated cases }\end{array}$ & $\begin{array}{l}\text { Proportion of } \\
\text { HCAI (\%) }\end{array}$ & Reference \\
\hline $\begin{array}{l}12 \text { months } 1983-1984, \\
\text { Maryland, USA }\end{array}$ & ICP & NS & Self-constructed & 2 & 690 & 242040 & 114 & 100 & 13 & Vlahov et al. ${ }^{11}$ \\
\hline $\begin{array}{l}6 \text { months, } 1984-1985 \text {, } \\
\text { Wisconsin, USA }\end{array}$ & TP & NS & CDC NNIS 1975 & 8 & 403 & 74370 & 3 & Unknown & 1 & $\begin{array}{l}\text { Scheckler and } \\
\text { Peterson }^{21}\end{array}$ \\
\hline 12 months, 1985-1986, USA & TP, CR & Daily & Based on CDC definitions & 1 & 166 & 60672 & 15 & Unknown & 4.5 & Schicker et al. ${ }^{22}$ \\
\hline $\begin{array}{l}3 \text { years, 1984-1987, California } \\
\text { USA }\end{array}$ & TP, CR & Weekly & Based on CDC definitions & 1 & 666 & 110746 & 11 & Unknown & 1 & Jackson et al. ${ }^{18}$ \\
\hline $\begin{array}{l}12 \text { months, 1982, Manitoba, } \\
\text { Canada }\end{array}$ & TP, CR, Q WR & $\begin{array}{l}2-5 \text { times per } \\
\text { week }\end{array}$ & Based on CDC definitions & 1 & 68 & 21000 & 19 & 12 & 17 & Nicolle et al. ${ }^{20}$ \\
\hline $\begin{array}{l}12 \text { months, } 1982-1983 \text {, } \\
\text { Pennsylvania, USA }\end{array}$ & TP, CR, WR & Weekly & Self-constructed & 1 & 111 & 15218 & 10 & 10 & 8 & Farber et al. ${ }^{16}$ \\
\hline $\begin{array}{l}9 \text { months, 1985-1986, Oregon, } \\
\text { USA }\end{array}$ & $\mathrm{TP}, \mathrm{CR}$ & NS & CDC NNIS 1975 & 1 & 231 & 26600 & 4 & 4 & 4 & $\begin{array}{l}\text { Jacobson and } \\
\text { Strausbaugh }\end{array}$ \\
\hline $\begin{array}{l}8 \text { months, } 1988-1989 \\
\text { Pennsylvania, USA }\end{array}$ & TP, CR, Q & Daily & Self-constructed & 3 & 572 & 137280 & 53 & Unknown & Unknown & Sims et al. ${ }^{23}$ \\
\hline $\begin{array}{l}12 \text { months, 1998-1989, } \\
\text { Germany }\end{array}$ & $\begin{array}{l}\text { TP, CR, } \\
\text { WR }\end{array}$ & 2-3 times weekly & Modified McGeer & 1 & 125 & 34793 & 43 & Unknown & 21 & Engelhart et al. ${ }^{6}$ \\
\hline $\begin{array}{l}30 \text { months, 1996-1998, Idaho, } \\
\text { USA }\end{array}$ & TP, Q & & McGeer & 6 & 655 & 328065 & 88 & 11 & 7 & Stevenson ${ }^{24}$ \\
\hline 18 months, Toronto, Canada & TP, Q & NS & McGeer & 21 & 763 & 339195 & 128 & Unknown & 10 & Liu et al. ${ }^{19}$ \\
\hline 12 months, 2001, Idaho, USA & $\begin{array}{l}\text { ICP, TP, CR, WR, } \\
\text { Q }\end{array}$ & NS & McGeer & 17 & 1273 & 472019 & 77 & Unknown & 4 & Stevenson et al. ${ }^{25}$ \\
\hline $\begin{array}{l}6 \text { months, 2006, Frankfurt, } \\
\text { Germany }\end{array}$ & $\mathrm{TP}, \mathrm{Q}$ & $1-2$ times weekly & Modified McGeer & 2 & 278 & 45710 & 87 & Unknown & Unknown & $\begin{array}{l}\text { Heudorf and } \\
\text { Schulte }\end{array}$ \\
\hline $\begin{array}{l}6 \text { months, 2004, Bergen, } \\
\text { Norway }\end{array}$ & TP, Q & Weekly & McGeer & 6 & 791 & 142688 & 60 & 57 & 8 & Eriksen et al. ${ }^{15}$ \\
\hline $\begin{array}{l}12 \text { months, 2003, Botucatu, } \\
\text { Brazil }\end{array}$ & TP, Q & NS & $\begin{array}{l}\text { Society for Healthcare } \\
\text { Epidemiology America }\end{array}$ & 1 & 55 & 20896 & 5 & Unknown & 7 & $\begin{array}{l}\text { Villas Boas and } \\
\text { Ferreira }^{26}\end{array}$ \\
\hline
\end{tabular}

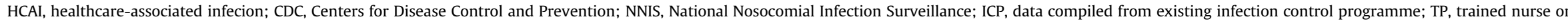
infection control practitioner collected data; CR, chart review to identify infections; $\mathrm{Q}$ questionnaires or standard forms used to record infection data; NS, not stated. 


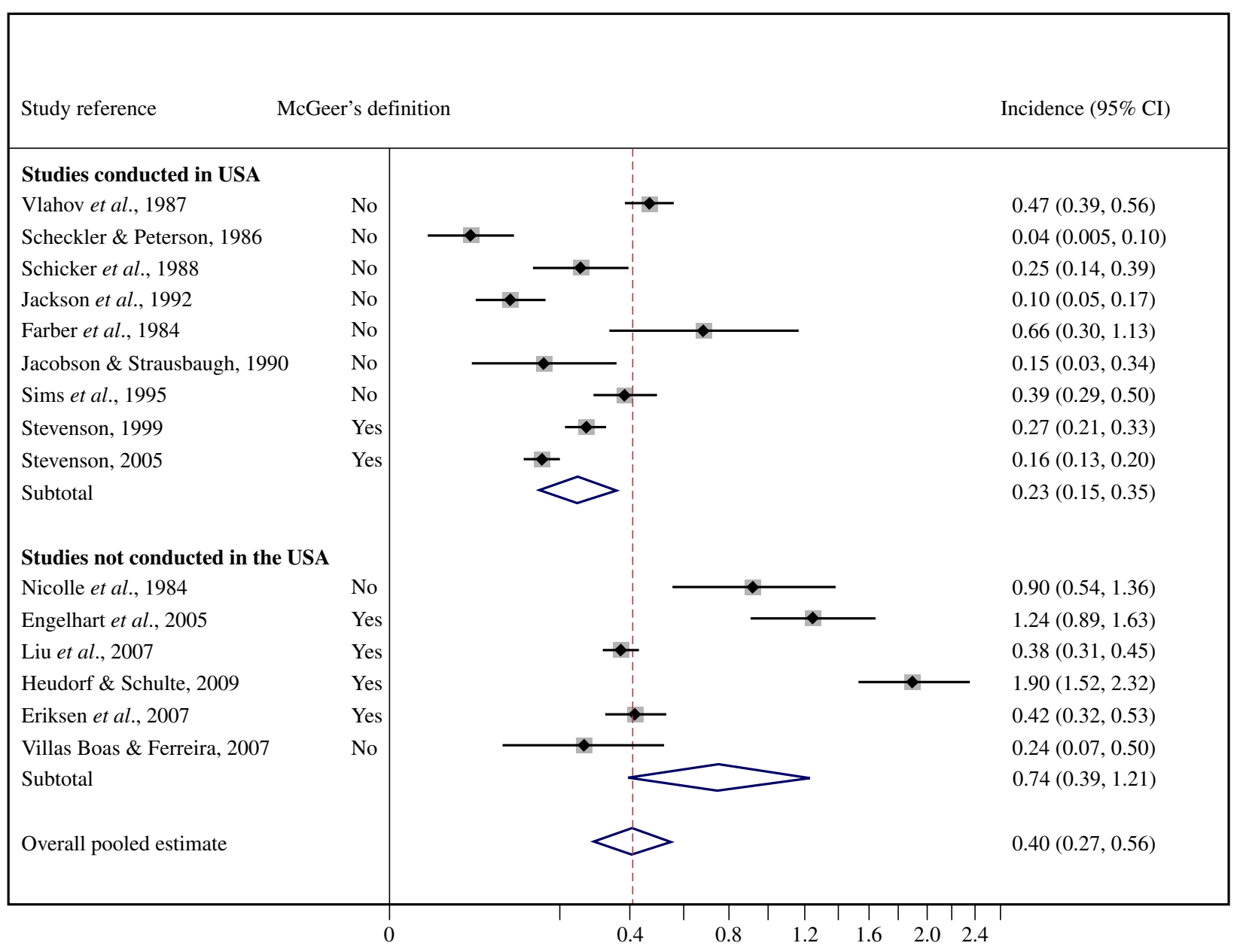

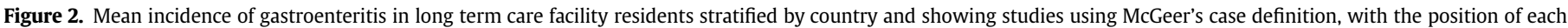
symbol representing each respective study and the horizontal line indicating the $95 \%$ confidence interval $(\mathrm{CI})$ of each study.

prevalence surveys were underpowered to study gastroenteritis with only two of five studies recording more than 10 cases each, making comparisons with incidence studies unreliable. ${ }^{34}$ Point prevalence studies also rarely take into account the likelihood of clustering for infections, which is high for gastroenteritis.

The occurrence of outbreaks influences the incidence of nosocomial infections and in the studies we examined investigators did not compare the incidence of epidemic and non-epidemic infections. It is important to consider outbreak-associated cases as a part of the burden of infection and to document their relative occurrence to sporadic cases. It is likely that some studies in our review included outbreak-associated cases that were not recognised as such or reported by authors. Unreported outbreak-associated cases could account for the significant heterogeneity we observed between studies of similar methods. The majority of outbreaks were small, although one study reported that two clusters accounted for all 96 cases in a single facility during a single year of surveillance. $^{11}$

Approximately 53\% of the studies were conducted before 1995 . However, we did not observe changes in the incidence of gastroenteritis in these studies over time. There are several reasons why we might have expected incidence to have changed, including: introduction of mandatory infection control surveillance, changes to the LTCF population and management practices in LTCFs, increased contact between LTCF residents and healthcare services, new diagnostic tests, and global spread of pathogens, such as norovirus. ${ }^{8,35}$
Diagnostic tests have highlighted the important role of norovirus and Clostridium difficile in the epidemiology of gastroenteritis in LTCF residents. ${ }^{36-38}$ A study in Ohio in 2006 reported that LTCF residents experienced 0.3 episodes of $C$. difficile infection per 1000 bed-days, although the proportion of cases experiencing symptoms was not reported. ${ }^{36}$ Similarly, studies of norovirus infections in LTCF residents show that these infections are one of the most common gastrointestinal pathogens and commonly result in outbreaks. ${ }^{38,39}$ There is a need for further work to clarify the role of different aetiological agents of gastroenteritis in facility residents, which may allow for specific interventions.

Many of the studies we included compared the incidence of different nosocomial infections, which means that they may not have been focused on recognition of gastroenteritis and were inadequately powered to study rarer conditions. In this metaanalysis, we pooled results across studies to assess the burden of gastroenteritis and were able to overcome the lack of larger studies. ${ }^{24}$ Although we did not observe a statistically significant difference based on whether or not the McGeer definition was used, in community-based surveys of gastroenteritis the choice of case definition makes considerable differences to the estimated incidence of gastroenteritis. ${ }^{40}$ In the 15 studies we reviewed, there were at least seven different case definitions used and only one study documented compliance with case definition by reporting symptoms. ${ }^{17}$ One study that specifically studied gastroenteritis in three LTCFs noted that one-third of potential illness events were excluded because they did not meet the case definition. ${ }^{23}$ 
We observed differences in the intensity of surveillance and the way that data were collected between studies, but data were insufficient for formal comparison. ${ }^{6}$ A limitation of our study was that we did not include unpublished datasets in our review. We were unable to locate unpublished and less accessible data despite extensive web-searching and evaluation of nursing and allied health databases, and so decided to rely solely on published data to maintain consistency within our review. ${ }^{4}$ We do not believe that this would have introduced significant biases, as gastroenteritis was only one of many infections under surveillance in nearly all studies. Approximately half of the studies included were identified through hand-searching of reference lists, highlighting the difficulties of appropriate indexing and reviewing the literature systematically. Despite this, we believe that we successfully included a high proportion of relevant published data, as this study was part of a broader literature review into gastroenteritis in institutionalised elderly. ${ }^{5}$

The incidence of reported gastroenteritis in LTCF residents was relatively low, nevertheless it is important that we learn more about this condition due to its potential for serious clinical outcomes and propensity to cause outbreaks. ${ }^{8}$ In this study, we were limited in the conclusions we could draw due to the small number of studies identified and the subtly different methods employed. We would encourage investigators to systematically collect and publish data on gastroenteritis in LTCF residents, and to consider the influence of the case definition, study design and outbreaks in calculations of incidence. In particular, it is important to learn more about the microbiological causes of gastroenteritis in LTCF residents.

\section{Acknowledgements}

We would like to thank Dr S. Hunt for her helpful comments on a draft of this manuscript.

\section{Conflict of interest statement}

None declared.

\section{Funding sources}

M. Kirk is a National Health and Medical Research Council scholar.

\section{References}

1. Htwe TH, Mushtaq A, Robinson SB, et al. Infection in the elderly. Infect Dis Clin North Am 2007;21:711-743.

2. Akhtar AJ. Acute diarrhea in frail elderly nursing home patients. J Am Med Dir Assoc 2003;4:34-39.

3. Frenzen PD. Deaths due to unknown foodborne agents. Emerg Infect Dis 2004;10:1536-1543.

4. Kirk M, Roberts L, Horvath J. Understanding gastroenteritis in elderly Australians. Med J Aust 2008;189:476-477.

5. Kirk M, Veitch M, Hall G. Gastroenteritis and foodborne disease in elderly people living in long-term care. Clin Infect Dis 2010;50:397-404.

6. Engelhart ST, Hanses-Derendorf L, Exner M, Kramer MH. Prospective surveillance for healthcare-associated infections in German nursing home residents. J Hosp Infect 2005;60:46-50.

7. Stevenson KB, Loeb M. Performance improvement in the long-term-care setting: building on the foundation of infection control. Infect Control Hosp Epidemiol 2004;25:72-79.

8. Smith PW, Bennett G, Bradley S, et al. SHEA/APIC guideline: infection prevention and control in the long-term care facility. Am J Infect Control 2008;36: 504-535.

9. Jacobson C, Strausbaugh LJ. Incidence and impact of infection in a nursing home care unit. Am J Infect Control 1990;18:151-159.

10. McGeer A, Campbell B, Emori TG, et al. Definitions of infection for surveillance in long-term care facilities. Am J Infect Control 1991;19:1-7.
11. Vlahov D, Tenney JH, Cervino KW, Shamer DK. Routine surveillance for infections in nursing homes: experience at two facilities. Am I Infect Control 1987; 15:47-53.

12. Freeman MF, Tukey JW. Transformations related to the angular and the square root. Ann Math Stat 1950;21:607-611.

13. Ioannidis JP. Interpretation of tests of heterogeneity and bias in meta-analysis. J Eval Clin Pract 2008;14:951-957.

14. Miller JT. The inverse of the Freeman-Tukey double arcsine transformation. Am Stat 1978;32:138.

15. Eriksen HM, Koch AM, Elstrom P, et al. Healthcare-associated infection among residents of long-term care facilities: a cohort and nested case-control study. J Hosp Infect 2007;65:334-340.

16. Farber BF, Brennen C, Puntereri AJ, Brody JP. A prospective study of nosocomial infections in a chronic care facility. J Am Geriatr Soc 1984;32:499-502.

17. Heudorf U, Schulte D. Surveillance of nosocomial infections in a long-term care facility. Incidence and risk factors. Bundesgesundheitsblatt Gesundheitsforschung Gesundheitsschutz 2009;52:732-743.

18. Jackson MM, Fierer J, Barrett-Connor E, et al. Intensive surveillance for infections in a three-year study of nursing home patients. Am J Epidemiol 1992;135 685-696.

19. Liu BA, McGeer A, McArthur MA, et al. Effect of multivitamin and mineral supplementation on episodes of infection in nursing home residents: a randomized, placebo-controlled study. J Am Geriatr Soc 2007;55:35-42.

20. Nicolle LE, McIntyre M, Zacharias H, MacDonell JA. Twelve-month surveillance of infections in institutionalized elderly men. J Am Geriatr Soc 1984;32: 513-519.

21. Scheckler WE, Peterson PJ. Infections and infection control among residents of eight rural Wisconsin nursing homes. Arch Intern Med 1986;146:1981-1984.

22. Schicker JM, Franson TR, Duthie Jr EH, LeClair SM. Comparison of methods for calculation and depiction of incidence infection rates in long-term care facilities. J Clin Epidemiol 1988;41:757-761.

23. Sims RV, Hauser RJ, Adewale AO, et al. Acute gastroenteritis in three community-based nursing homes. J Gerontol A Biol Sci Med Sci 1995;50: M252-M256.

24. Stevenson KB. Regional data set of infection rates for long-term care facilities: description of a valuable benchmarking tool. Am J Infect Control 1999;27: 20-26.

25. Stevenson KB, Moore J, Colwell H, Sleeper B. Standardized infection surveillance in long-term care: interfacility comparisons from a regional cohort of facilities. Infect Control Hosp Epidemiol 2005;26:231-238.

26. Villas Boas PJ, Ferreira AL. Infection in elderly interned in long-term care facilities. Rev Assoc Med Bras 2007;53:126-129.

27. Centers for Disease Control. National Nosocomial Inspection Study: site definitions manual. Atlanta, GA: CDC; 1975.

28. Ozfoodnet Network. Monitoring the incidence and causes of diseases potentially transmitted by food in Australia: annual report of the Ozfoodnet Network, 2007. Commun Dis Intell 2008;32:400-424

29. Doyle TJ, Stark L, Hammond R, Hopkins RS. Outbreaks of noroviral gastroenteritis in Florida, 2006-2007. Epidemiol Infect 2009;137:617-625.

30. Scallan E, Majowicz SE, Hall G, et al. Prevalence of diarrhoea in the community in Australia, Canada, Ireland, and the United States. Int J Epidemiol 2005;34: 454-460.

31. French Prevalence Survey Study Group. Prevalence of nosocomial infections in France: results of the nationwide survey in 1996. J Hosp Infect 2000;46 186-193.

32. Garibaldi RA, Brodine S, Matsumiya S. Infections among patients in nursing homes: policies, prevalence, problems. N Engl J Med 1981;305:731-735.

33. Magaziner J, Tenney JH, DeForge B, et al. Prevalence and characteristics of nursing home-acquired infections in the aged. J Am Geriatr Soc 1991;39: 1071-1078.

34. Humphreys H, Smyth ET. Prevalence surveys of healthcare-associated infections: what do they tell us, if anything? Clin Microbiol Infect 2006:12:2-4.

35. Lopman B, Vennema $\mathrm{H}$, Kohli E, et al. Increase in viral gastroenteritis outbreaks in Europe and epidemic spread of new norovirus variant. Lancet 2004;363: 682-688.

36. Campbell RJ, Giljahn L, Machesky K, et al. Clostridium difficile infection in Ohio hospitals and nursing homes during 2006. Infect Control Hosp Epidemiol 2009;30:526-533.

37. Laffan AM, Bellantoni MF, Greenough 3rd WB, Zenilman JM. Burden of Clostridium difficile-associated diarrhea in a long-term care facility. J Am Geriatr Soc 2006;54:1068-1073.

38. Lopman BA, Andrews N, Sarangi J, et al. Institutional risk factors for outbreaks of nosocomial gastroenteritis: survival analysis of a cohort of hospital units in South-west England, 2002-2003. J Hosp Infect 2005;60:135-143.

39. Godoy P, Dominguez A, Alvarez J, et al. High incidence of outbreaks of norovirus GGII.4 in hospitals and nursing homes in Catalonia. J Hosp Infect 2009;72: 275-277.

40. Majowicz SE, Hall G, Scallan E, et al. A common, symptom-based case definition for gastroenteritis. Epidemiol Infect 2008;136:886-894. 